\title{
O gênero acadêmico em questão: uma análise sociorretórica de resumos de dissertações de mestrado do projeto Teletandem Brasil
}

\section{The Academic Genre in Question: a Social-Rhetorical Analysis of Master's Theses in Teletandem Brazil Project}

\author{
Maisa de Alcântara Zakir* \\ Universidade Estadual Paulista \\ São José do Rio Preto - São Paulo / Brasil \\ Ludmila Belotti Andreu-Funo** \\ Universidade Estadual Paulista \\ São José do Rio Preto - São Paulo / Brasil
}

\begin{abstract}
RESUMO: O objetivo deste trabalho é investigar o gênero acadêmico resumo de dissertação de mestrado no contexto do projeto de pesquisa Teletandem Brasil: Línguas Estrangeiras para Todos. Tomando como ponto de partida as concepções de gênero textual da perspectiva sociorretórica, foram analisados dez resumos de dissertações de mestrado (um gênero já legitimado) vinculadas ao referido projeto (um contexto relativamente novo). Como resultado da análise, foi depreendida a ocorrência de um fenômeno ora intitulado "diminuição de esforço retórico", que consiste no apagamento de unidades retóricas que justifiquem a validade das pesquisas descritas nos resumos analisados. Entre as contribuiçóes do artigo, podem ser destacadas reflexões pertinentes tanto às comunidades discursivas que sustentam os gêneros acadêmicos quanto aos pesquisadores que aspiram um lugar nesse nicho.
\end{abstract}

PALAVRAS-CHAVE: comunidades discursivas; gênero acadêmico; perspectiva sociorretórica.

ABSTRACT: The goal of this paper is to investigate the academic genre abstract of master's thesis in the context of the research project Teletandem Brasil: foreign languages for all. Taking as starting point the concepts of genre from the socialrhetorical perspective we analyzed ten abstracts of theses (a genre which is already

\footnotetext{
*maisazakir@gmail.com

**1bandreu@hotmail.com
} 
legitimized) related to that project (which is a relatively new context). As a result of the analysis, we noticed the occurrence of a phenomenon that we called "reduction of rhetorical effort", which consists in erasing rhetorical units that justify the validity of the research described in the abstracts analyzed. Among the contributions of this paper, we can highlight relevant reflections not only to the discourse communities that support the academic genre but also to the researchers who aspire to a place in this niche.

KEYWORDS: discourse communities; academic genre; social-rhetorical perspective.

\section{Introdução}

O conceito de gêneros textuais tem sido muito difundido nos âmbitos acadêmico e educacional e, no Brasil, esse crescimento de trabalhos voltados ao ensino e à pesquisa da língua escrita com base em gêneros pôde ser observado de modo mais evidente a partir de 1995 (MOTTA-ROTH, 2008).

Diferentes perspectivas teóricas têm norteado os estudos de gênero textual: as abordagens sociossemióticas, cujos principais representantes são Halliday, Hasan, Martin, Fairclough e Kress, privilegiam um enfoque na léxico-gramática e nas funções desempenhadas por ela nos contextos sociais (MOTTA-ROTH, 2008); as abordagens sociodiscursivas, difundidas pelos estudos de Bakhtin, Adam, Bronckart, Schewnely e Dolz, Maingueneau, Rojo e Machado, focalizam um caráter mais social do que estrutural da linguagem; já as abordagens sociorretóricas, que têm em Swales, Miller e Bhatia seus principais nomes, trabalham principalmente com a organização retórica e os propósitos comunicativos do texto.

Evidenciando essa diversidade de abordagens que têm os gêneros textuais como objeto de estudo, Bonini (2004) traz um panorama a respeito de como o referido conceito tem sido compreendido segundo diferentes perspectivas de pesquisa. $\mathrm{O}$ autor apresenta doze definiçóes de gênero elaboradas por especialistas e afirma que a presença de elementos eventualmente divergentes nas formulações desses "autores representativos do campo" (BONINI, 2004, p. 2) demonstra a complexidade do tema e a grande dificuldade que existe na tarefa de se tentar explicar, ou delimitar para fins didáticos, o que venha a ser um gênero.

Embora exista essa diversidade de definições do conceito de gênero, segundo Motta-Roth (2008), parece existir uma coincidência entre as diferentes escolas que têm o gênero como objeto de estudo quanto aos seguintes pontos: 1) Gêneros são usos da linguagem associados a atividades 
sociais; e 2) Essas ações discursivas são recorrentes e, por isso, têm algum grau de estabilidade na forma, no conteúdo e no estilo.

Ainda assim, conforme demonstra Bonini (2004), normalmente, a maioria das pessoas adota uma representação ou uma imagem de prototipicidade das materializaçôes textuais que devem estar vinculadas a este ou àquele gênero. Contudo, ao se buscarem maiores detalhamentos, essas representações mostram-se incapazes de "abarcar a complexidade do fenômeno" (BONINI, 2004, p. 1).

Além disso, Bonini (2004) destaca em seu trabalho as definições de gênero que tomam a materialidade textual como exemplos de gêneros textuais propriamente ditos, e não como produções pertencentes a um dado gênero, podendo ser este o gênero literário, jornalístico, acadêmico etc.

Nosso interesse pelas definições apresentadas por Bonini (2004) recai na percepção da complexidade do assunto e na necessidade iminente de que se teçam maiores subsídios para a compreensão dos gêneros textuais. A partir disso, nosso objetivo será, então, investigar o gênero acadêmico resumo de dissertação de mestrado, dentro de um contexto bastante específico, o projeto de pesquisa Teletandem Brasil: Línguas Estrangeiras para Todos ${ }^{1}$ (doravante TTB). Serão analisados dez resumos, escritos em língua portuguesa, de dissertaçóes de mestrado de pesquisas vinculadas ao referido projeto, cujo foco é investigar o ensino e aprendizagem de línguas estrangeiras em contextos virtuais com o uso de tecnologia para interação dos participantes.

Desse modo, tomando como ponto de partida as concepções de gênero elaboradas por Swales (1990; 2004) e Bhatia (1993), nossas reflexões estarão voltadas para um gênero acadêmico já legitimado (o resumo de dissertação de mestrado), mas como parte de um projeto relativamente novo (o projeto TTB) dentro de uma determinada comunidade discursiva (os pesquisadores da área de Linguística Aplicada). Consideraremos essas duas características para a verificação de possíveis apagamentos de certas unidades retóricas nos resumos estudados, conforme veremos na análise.

\section{Fundamentação teórica}

Diante da diversidade de conceitos de gênero nas diferentes áreas em que é tomado como objeto de estudo, neste trabalho filiamo-nos à abordagem

${ }^{1}$ Para maiores informaçôes sobre o projeto, vide o site <www.teletandembrasil.org>. 
sociorretórica do estudo de gênero. Considerando que a proposta de Swales $(1990$; 2004) era trabalhar com gêneros acadêmicos, que são relativamente padronizados, nossa escolha se deve ao fato de que o objeto de estudo deste trabalho - resumos de dissertações de mestrado - é uma manifestação do gênero acadêmico, pertence a uma comunidade discursiva e apresenta propósitos comunicativos específicos na área em que se insere.

Entendemos que a grande contribuição de Swales está no caráter pedagógico do modelo proposto por ele e que será apresentado mais adiante. Ainda que existam críticas, como o próprio Swales (1990, p. 10, tradução nossa) previa ao afirmar que "[a]cusaçôes de repetir fórmulas são certamente bastante frequentes nas discussōes de análise de gêneros e seus usos e abusos", concordamos com Aranha (1996), para quem

em termos didáticos, devamos partir do maior para o menor, ou seja, da macro-estrutura que determina o reconhecimento do gênero para as escolhas lingüísticas apropriadas ao discurso acadêmico, sempre tendo o domínio da língua inglesa como pressuposto. (ARANHA, 1996, p. 10-11).

É neste sentido que as ideias de Swales e suas considerações sobre o gênero serão o fundamento do estudo que ora propomos. Conforme afirma Aranha na citação acima, o trabalho de Swales sempre esteve voltado à aprendizagem da língua inglesa, tendo em vista que esta é a língua na qual são escritos e divulgados os mais importantes trabalhos acadêmicos no mundo (SWALES, 1990, p. 1). Além de ser bastante difundido entre as pesquisas de inglês para fins específicos e acadêmicos (ESP e EAP, nas siglas em inglês), o trabalho de Swales também tem inspirado estudos de gêneros acadêmicos (e até não acadêmicos) escritos em outras línguas. ${ }^{3}$ Desse modo, entendemos que pensar a aplicação da proposta de Swales para os gêneros textuais, sobretudo os acadêmicos, contribui para o sucesso de aspirantes a membros de determinada comunidade discursiva de modo que passem a se inserir na compreensão e na produção dos gêneros que ali se constituem.

\footnotetext{
2 "Accusations of formulaic parroting are certainly frequent enough in discussions of genre analysis and its uses and abuses."

${ }^{3}$ Exemplos de pesquisas que têm sido inspiradas no trabalho de Swales podem ser encontrados no livro Gêneros textuais e comunidades discursivas: um diálogo com John Swales, organizado por Biasi-Rodrigues, Araújo e Souza (2009).
} 
A primeira definição de gênero que será considerada neste trabalho, e da qual partimos, é, portanto, a de John Swales (1990). O pesquisador apoiouse em quatro áreas de estudo (folclore, literatura, linguística e retórica) para formular o conceito de que:

Um gênero compreende uma classe de eventos comunicativos, cujos membros compartilham um dado conjunto de propósitos comunicativos. Esses propósitos são reconhecidos pelos membros especialistas da comunidade discursiva de origem e, portanto, constituem a base lógica [rationale] para o gênero. Essa base molda a estrutura esquemática do discurso e influencia e coloca limites à escolha de conteúdo e de estilo. O propósito comunicativo é tanto um critério privilegiado como um critério que opera para manter o escopo de um gênero tal como aqui concebido, estritamente focado em uma ação retórica comparável. Além do propósito, os exemplares de um gênero exibem vários padrões de similaridade em termos de estrutura, estilo, conteúdo e audiência pretendida. Se todas as expectativas de probabilidade mais alta forem realizadas, o exemplar será visto como prototípico pela comunidade discursiva de origem. Os nomes dos gêneros herdados e produzidos pelas comunidades discursivas e importados por outras constituem uma valiosa comunicação etnográfica, mas tipicamente necessitam de validação posterior. (SWALES, 1990, p. 58, tradução e grifos nossos). ${ }^{4}$

No momento em que elaborou a definição acima - a qual é importante referência nos estudos de gênero até hoje - Swales indicou que o critério principal para o reconhecimento de um gênero era o seu propósito

\footnotetext{
4 "A genre comprises a class of communicative events, the members of which share some set of communicative purposes. These purposes are recognized by the expert members of the parent discourse community, and thereby constitute the rationale for the genre. This rationale shapes the schematic structure of the discourse and influences and constrains choice of content and style. Communicative purpose is both a privileged criterion and one that operates to keep the scope of a genre as here conceived narrowly focused in comparable rhetorical action. In addition to purpose, exemplars of a genre exhibit various patterns of similarity in terms of structure, style, content and intended audience. If all high probability expectations are realized, the exemplar will be viewed as prototypical by the parent discourse community. The genre names inherited and produced by discourse communities and imported by others constitute valuable ethnographic communication, but typically need further validation."
} 
comunicativo. Além disso, essa definição implicava considerar, ainda, que o gênero se constituía de cinco características, que resumimos aqui a partir da descrição de Hemais e Biasi-Rodrigues (2005, p. 113-114):

1. O gênero é uma classe de eventos comunicativos, sendo o evento uma situação em que a linguagem verbal tem um papel significativo e indispensável;

2. Em uma classe de eventos comunicativos, os eventos compartilham de um propósito comunicativo;

3. Prototipicidade: um texto será classificado como sendo do gênero se possuir os traços especificados na definição do gênero.

4. Razão subjacente: significa a lógica do gênero, e nessa lógica os membros da comunidade reconhecem o gênero.

5. Terminologia elaborada pela comunidade discursiva: os termos atribuídos aos gêneros são indicadores de como os membros mais experientes e ativos da comunidade, que dão nomes aos gêneros, entendem a ação retórica das classes de eventos comunicativos.

Embora essas características continuem balizando a noção de gênero na abordagem sociorretórica até hoje, Swales revisitou a compreensão de gênero, sobretudo no que tange às noções de comunidade discursiva e propósito comunicativo.

A noção de comunidade discursiva, especialmente, evoluiu para a caracterização de um grupo de pessoas que trabalham no mesmo lugar e mantêm um repertório de gêneros, que possuem traços retóricos claros e validam as atividades da comunidade. A novidade e a evolução passaram a fazer parte da concepção de comunidade discursiva, consideradas na medida em que os seus membros podem desenvolver novos gêneros. (BIASI-RODRIGUES; ARAÚJO; SOUZA, 2009, p. 31-32).

A partir das contribuições de autores como Bhatia (1993), Orlikowski e Yates (1994), Bex (1996) e Askehave (1998), Swales repensa também a questão do propósito comunicativo, ao reconhecer a dificuldade de se precisar o conceito. Na formulação do conceito de gênero de 1990, Swales entendia que o propósito comunicativo constituía-se como o critério mais importante para o reconhecimento de um gênero. No entanto, posteriormente, em artigo escrito com Askehave em 2001, Swales considera que o propósito comunicativo não é tão visível quanto à forma e que, devido a isso, não seria mais o critério "básico e fundamental", mas continuaria mantido como um critério privilegiado para o reconhecimento do gênero. Essa mudança de perspectiva 
com relação ao propósito comunicativo se deveu, conforme afirma BiasiRodrigues (2007, p. 731), ao reconhecimento dos autores de que "embora os membros de uma comunidade discursiva tenham grande conhecimento dos gêneros, eles podem não estar absolutamente de acordo com o propósito de um determinado gênero e reorientar a sua finalidade."

É em Research Genres: Explorations and Applications, livro publicado em 2004, que Swales ressignifica o papel do propósito comunicativo. A partir de uma pesquisa realizada com cartas de recomendação, o autor constata que é difícil identificar o propósito de um gênero, devido ao fato de que podem haver "múltiplos propósitos comunicativos que, em dadas circunstâncias de uso dos gêneros, não são evidentes à primeira vista." (BIASI-RODRIGUES, 2007, p. 732).

Como dissemos anteriormente, embora tenham ocorrido mudanças no conceito de gênero proposto por Swales em 1990, a compreensão do propósito comunicativo continua sendo central para a abordagem sociorretórica. Apesar de fazer algumas elaboraçôes com relação ao conceito de Swales (1990), Bhatia, outro autor cujas pesquisas são um importante fundamento deste trabalho, também defende que o propósito comunicativo seja um critério privilegiado para o reconhecimento de cada gênero. Para Bhatia (1993), o gênero é

um exemplo de realização bem sucedida de um propósito comunicativo específico, usando um conhecimento convencional de recursos linguísticos e discursivos. Visto que cada gênero, em certos aspectos, estrutura o estreito mundo da experiência ou realidade de um modo particular, a implicação é a de que a mesma experiência ou realidade vai requerer um modo diferente de estruturação, se for para operar em um gênero diferente. (BHATIA, 1993, p. 116, tradução nossa). ${ }^{5}$

No livro Analysing Genre: Language Use in Professional Settings, publicado em 1993, Bhatia, além de definir gênero, ilustra, por meio da análise de diferentes textos, o papel do propósito comunicativo no reconhecimento dos gêneros. $\mathrm{Na}$ referida obra, como já mencionado na introdução, interessa-nos, sobretudo, o gênero acadêmico resumo de artigos científicos, que é definido por Bhatia (1993,

\footnotetext{
5 “[...] an instance of a successful achievement of a specific communicative purpose using conventionalized knowledge of linguistic and discoursal resources. Since each genre, in certain important respects, structures the narrow world of experience or reality in a particular way, the implication is that the same experience or reality will require a different way of structuring, if one were to operate in a different genre."
} 
p. 78, tradução nossa) como "uma descrição ou resumo factual de um relatório muito mais longo, e tem a finalidade de dar ao leitor um conhecimento exato e conciso do artigo inteiro." Vale ressaltar que, para Bhatia (1993), o resumo é um gênero e não apenas uma seção do artigo científico. $O$ autor, que foi quem primeiro investigou esse gênero na perspectiva da sociorretórica, considera que um bom resumo deve responder às seguintes perguntas: o que o autor fez; como o fez; o que encontrou e o que concluiu.

Em suas pesquisas sobre o gênero resumo de artigos científicos, Bhatia (1993, p. 78-79) identificou quatro movimentos recorrentes, que podem ser sintetizados no quadro abaixo, elaborado por Carvalho (2010):

\section{QUADRO 1}

Padrão descritivo da organização textual dos resumos de artigos de pesquisa, segundo Bhatia (1993)

\begin{tabular}{|c|}
\hline INTRODUZIR O PROPÓSITO (move 1) \\
\hline Estratégia 1: indicando a intenção do autor e/ou \\
\hline Estratégia 2: levantando a hipótese e/ou \\
\hline Estratégia 3: apontando objetivos e/ou \\
\hline Estratégia 4: apresentando o problema a ser solucionado \\
\hline DESCREVER A METODOLOGIA (move 2) \\
\hline Estratégia 1: apresentando o quadro teórico metodológico adotado e/ou \\
\hline Estratégia 2: incluindo informaçōes sobre o corpus e/ou \\
\hline Estratégia 3: descrevendo os procedimentos ou métodos utilizados e/ ou \\
\hline Estratégia 4: indicando o escopo da pesquisa \\
\hline SINTETIZAR OS RESULTADOS (move 3) \\
\hline Estratégia 1: apontando observações sobre os dados analisados e/ou \\
\hline Estratégia 2: apresentando os resultados encontrados e/ou \\
\hline Estratégia 3: sugerindo soluções para o problema (caso tenha sido apontado no primeiro move) \\
\hline APRESENTAR CONCLUSÕES (move 4) \\
\hline Estratégia 1: interpretar os resultados e/ou \\
\hline Estratégia 2: apontando inferências sobre os resultados e/ou \\
\hline Estratégia 3: indicando implicações acerca dos resultados obtidos e/ ou \\
\hline Estratégia 4: apontando aplicações dos estudos obtidos \\
\hline
\end{tabular}

Fonte: CARVALHO, 2010, p. 118.

6 "[...] a description or factual summary of the much longer report, and is meant to give the reader an exact and concise knowledge of the full article." 
Assim como Bhatia, vários autores, partindo da concepção de Swales sobre gênero, e valendo-se do caráter didático do modelo CARS (Create a Research Space), ${ }^{7}$ criado por ele, passaram a adotar a proposta metodológica de se considerar outros gêneros textuais (e não apenas o gênero introdução de artigos cientificos) como um conjunto de movimentos retóricos que tem propósitos comunicativos. O modelo CARS, cuja primeira versão foi apresentada em 1981 e alterada com base em experiências de outros pesquisadores, foi desenvolvido a partir de um amplo estudo investigativo de Swales sobre introduções de artigos de pesquisa com o propósito de representar a organização textual dessas introduções para fins didático-pedagógicos.

Um exemplo disso é o quadro que elaboramos a partir do texto de Hemais e Biasi-Rodrigues (2005), no qual procuramos evidenciar alguns trabalhos que tentaram se basear no modelo CARS para diferentes gêneros textuais acadêmicos ou não:

\section{QUADRO 2}

Tentativas de aplicação do modelo CARS

\begin{tabular}{l|l}
\hline PESQUISADORES & APLICAÇÕES DO MODELO CARS \\
\hline Wood (1982) & em seçôes de métodos e resultados em textos de química \\
\hline Dudley-Evans (1986) & em seções de introdução e discussão de dissertações de mestrado \\
\hline Crookes (1987) & em textos científicos de diversas áreas \\
\hline $\begin{array}{l}\text { Motta-Roth (1995) } \\
\text { e Araújo (1996) }\end{array}$ & em resenhas de livros \\
\hline Aranha (1996) & em introduções de artigos de pesquisa \\
\hline Santos (1995); Motta-Roth & em resumos de artigos de pesquisa \\
\hline e Hendges (1996) & \\
\hline Biasi-Rodrigues (1998) & em resumos de dissertações \\
\hline Bernardino (2000) & em depoimentos dos alcoólicos anônimos \\
\hline Hendges (2001) & em seção de revisão da literatura \\
\hline Bezerra (2001) & em resenhas acadêmicas \\
\hline Dudley-Evans (2001) & em ensaios acadêmicos \\
\hline
\end{tabular}

Fonte: Elaboração própria, a partir do texto de Hemais e Biasi-Rodrigues (2005, p. 122).

${ }^{7}$ Tendo em vista que o modelo CARS não é o foco do presente artigo, fazemos uma referência à proposta desse autor e sugerimos a leitura de Swales (1990, p. 141) para um maior detalhamento do referido modelo, que inspirou outros subsequentes. 
Assim como Biasi-Rodrigues (1998), que em sua tese de doutorado, investigou resumos de dissertações de mestrado da área de linguística, o trabalho que ora propomos também tem como foco esse gênero. No entanto, a especificidade de nossa proposta está no fato de que teremos como objeto de análise resumos de dissertaçôes de mestrado vinculadas a uma área relativamente nova na Linguística Aplicada: o ensino e aprendizagem de línguas em Teletandem, que ocorre em contextos virtuais, por meio do uso de tecnologias de informação e comunicação.

Para realizar a análise, teremos como elementos norteadores dois pressupostos principais a partir dos quais Bhatia (1997) tece considerações importantes: a) as formaçōes discursivas existem mediante negociação social, e b) os gêneros, em sua discursividade, são tanto socialmente construídos quanto controlados por práticas sociais.

Visando a discutir a relação entre poder e política em gêneros, a proposta de Bhatia (1997) é debater a) as restrições que norteiam as materializações que se pretendem pertencedoras a determinados gêneros e suas implicações, e b) os saberes ou diretrizes cujo domínio tanto pode levar aspirantes à condição de novos membros dessas "comunidades discursivas", quanto permitirá o uso de uma espécie de licença para os membros mais experientes que queiram ou precisem explorar e até mesmo subverter tais diretrizes (BHATIA, 1997, p. 361).

Esses pressupostos nos são fundamentais, justamente porque estamos, aqui, propondo uma análise de um gênero já constituído e legitimado na comunidade discursiva da Linguística Aplicada (o resumo de dissertação de mestrado), que poderáse (re)constituir no contexto novo (o projeto TTB) no qual se insere.

A abordagem de Bhatia (1997) se dá por um viés que também ressalta a complexidade da formação dos construtos reconhecidos como gêneros, uma vez que o autor reconhece nos gêneros sua dinamicidade, uma tendência à manutenção de sua integridade - generic integrity - e, concomitantemente, uma tendência à busca por inovaçôes - propensity for innovation - características definidas por Bhatia como complementares entre si e interdependentes (BHATIA, 1997, p. 360).

Dessa forma, estudos sobre as materializaçóes reconhecidas por uma dada comunidade discursiva como pertencentes ou adequadas a um dado gênero são de suma importância para o aprofundamento e atualização dos saberes nessa área dos estudos linguísticos. Isso porque tanto os gêneros quanto as comunidades discursivas mostram-se complexos e dinâmicos, ao subsidiarem as práticas sociais que legitimam ou não as manifestações textuais que reconhecemos como pertencentes a um gênero em detrimento de outro. 


\section{Análise dos dados}

Tendo as reflexôes sobre a complexidade e a dinamicidade dos gêneros como pressupostos para o estudo que ora se apresenta neste trabalho, propomos uma análise de resumos de dez dissertaçôes de mestrado, publicadas em língua portuguesa entre 2008 e 2011, que resultaram de pesquisas realizadas no Projeto TTB. ${ }^{8}$

Tais resumos foram agrupados em documento do Word, identificados com números de 1 até 10 , respeitando a ordem cronológica de publicação das dissertaçôes. Além disso, esses textos tiveram suas linhas discriminadas e alguns trechos demarcados com cores distintas, tendo sido utilizada uma cor para cada recorrência que pudesse ser identificada como uma possível unidade temática básica. As recorrências destacadas por meio de uma análise comparativa e contrastiva entre os resumos foram:

\section{QUADRO 3}

Procedimento empregado na marcação de recorrências das quais se pudessem depreender unidades ou subunidades retóricas

\begin{tabular}{l|l}
\hline Cores & \multicolumn{1}{|c}{ Classificação das ocorrências } \\
\hline Cinza & Citando conhecimentos prévios/ pesquisas que embasam o estudo \\
\hline Amarelo & Apresentando a “filiação" de sua pesquisa \\
\hline Rosa & Apresentando os objetivos do seu estudo \\
\hline Verde & $\begin{array}{l}\text { Expondo característica do método utilizado para coleta, sistematização } \\
\text { e análise dos dados }\end{array}$ \\
\hline Violeta & Expondo orientação metodológica do estudo \\
\hline Azul & Apresentando os resultados da pesquisa \\
\hline
\end{tabular}

Fonte: Elaboração própria.

A ordenação dos resumos no corpus seguiu a mesma ordem de postagem na página de internet do projeto TTB, que, por sua vez, também respeita a ordem cronológica das defesas dessas dissertações:

\footnotetext{
${ }^{8}$ Os dez resumos de dissertações de mestrado que são objeto de nossa análise estão disponíveis na página do projeto TTB, em <http://www.teletandembrasil.org/ page.asp?Page=25>. Acesso em: 10 jul. 2013.
} 


\section{QUADRO 4}

Ordenação dos resumos de dissertações de mestrado abordados neste estudo

\begin{tabular}{c|l|c}
\hline Número & \multicolumn{1}{|c}{ Título da dissertação } & Ano \\
\hline 1 & $\begin{array}{l}\text { Características da interação no contexto de aprendizagem } \\
\text { in-tandem }\end{array}$ & 2008 \\
\hline 2 & $\begin{array}{l}\text { Gerenciamento e estratégias pedagógicas na mediação dos } \\
\text { pares no Teletandem e seus reflexos para as práticas } \\
\text { pedagógicas dos interagentes }\end{array}$ & 2008 \\
\hline 3 & $\begin{array}{l}\text { O desenvolvimento intra-interlinguístico in-tandem } \\
\text { a distância (Português e Espanhol) }\end{array}$ & 2008 \\
\hline 4 & $\begin{array}{l}\text { A (re)construção das crenças do par interagente e dos } \\
\text { professores-mediadores no Teletandem }\end{array}$ & 2008 \\
\hline 6 & $\begin{array}{l}\text { Crenças e práticas de avaliação no processo interativo e na } \\
\text { mediação de um par no tandem a distância: um estudo de caso }\end{array}$ & 2008 \\
\hline 7 & $\begin{array}{l}\text { A autonomia no processo de ensino e aprendizagem de línguas } \\
\text { em ambiente virtual (Teletandem) }\end{array}$ & $\begin{array}{l}\text { Crenças sobre a Língua Inglesa: o antiamericanismo e sua } \\
\text { relação com o processo de ensino - aprendizagem de } \\
\text { professores em formação }\end{array}$ \\
\hline 8 & $\begin{array}{l}\text { A gramática em contexto Teletandem e em livros didáticos } \\
\text { de Português como Língua Estrangeira }\end{array}$ & 2009 \\
\hline 9 & $\begin{array}{l}\text { Teletandem: sessóes de orientação e suas Perspectivas para o } \\
\text { curso de Letras }\end{array}$ & 2010 \\
\hline 10 & $\begin{array}{l}\text { Teletandem e formação contínua de professores vinculados à } \\
\text { rede pública de ensino do interior paulista: um estudo de caso }\end{array}$ & 2011 \\
\hline
\end{tabular}

Fonte: Elaboração própria.

Neste estudo, em consonância com o trabalho de Biasi-Rodrigues (1998), consideramos como unidades retóricas (UR) os trechos extraídos dos resumos das dissertações que analisamos. Definimos como URs essas unidades temáticas que se caracterizam por propósitos específicos dentro do gênero que estudamos. Para uma melhor caracterização desse critério, estabelecemos subunidades retóricas $(\mathrm{S})$, as quais delimitam mais especificamente esses propósitos comunicativos dentro das URs.

Para identificá-las, destacamos aspectos estruturais do texto, tais como os seguintes marcadores textuais, que serviram para a delimitação do que veio a ser a UR3-S4 (Unidade Retórica 3-Subunidade 4): "A presente pesquisa configura-se como [...]" (Apêndice 10, linha 6); "Trata-se de uma pesquisa 
qualitativa [...]" (Apêndice 6, linha 17); "Este trabalho é um estudo de caso [...]" (Apêndice 5, linha 19); "O presente trabalho caracteriza-se como [...]" (Apêndice 3, linha 12). A consideração desses padrões estruturais serviu como ponto de partida no processo de discriminação das predominâncias que ajudaram a demarcar a referida UR.

Com a leitura comparativa dos resumos, a discriminação dos referidos marcadores textuais e a consideração de características contextuais acerca da comunidade discursiva à qual os pesquisadores que redigiram os resumos supracitados estão vinculados, chegamos à elaboração do seguinte quadro, em que UR refere-se a unidades retóricas e $S$ a subunidades:

\section{QUADRO 5}

Unidades retóricas (URs) e subunidades (S) identificadas através da análise de resumos de dissertaçôes vinculadas ao projeto TTB

\section{UR1: Citando conhecimentos prévios / pesquisas que embasam o estudo}

S1: Enfatiza conhecimentos científicos sobre ensino/aprendizagem de idiomas já sistematizados pela comunidade discursiva à qual pertence (de linguistas e linguistas aplicados); e/ou

S2: Enfatiza a relação tecnologias e educação; e/ou

S3: Enfatiza áreas de pesquisa cujos construtos servirão de subsídio para seu estudo.

\section{UR2: Apresentando uma espécie de filiação (direta ou indireta) ao projeto TTB}

S1: Apresenta filiação direta: indica que a dissertação "se insere", "se enquadra", "está vinculada" ou "é parte" do referido projeto; e/ou

S2: Apresenta filiação indireta: Cita que o estudo tem suas ações desenvolvidas em contextos em que se pratica Teletandem, mas não menciona diretamente que a pesquisa está vinculada ao projeto TTB.

\section{UR3: Apresentando a pesquisa}

S1: Apresenta os objetivos da pesquisa; e

S2: Apresenta os procedimentos de coleta dos dados (observação, gravação, aplicação de questionário) e de sistematização desses dados (transcrição) em corpus (método I); e

S3: Apresenta os procedimentos de análise - interpretação, triangulação, inferência, mapeamento (método II); e

S4: Apresenta a metodologia que orienta as ações da pesquisa (Estudo qualitativo, etnográfico, estudo de caso, paradigma interpretativista etc.); e

S5: Apresenta os resultados da pesquisa.

Fonte: Elaboração própria. 
Os pesquisadores que redigiram os resumos de dissertação de mestrado analisados neste estudo estão vinculados ao projeto temático TTB, formalizado com o apoio da FAPESP (Fundação de Amparo à Pesquisa do Estado de São Paulo) em 2006. Embora ainda existam pesquisas em andamento, as ações previstas pelo projeto temático TTB foram concluídas no segundo semestre de 2009, em sua terceira fase, cujo objetivo final era a formação de professoresmediadores em contexto Teletandem de ensino e de aprendizagem de línguas (ver TELLES, 2006). Logo, trata-se de um grupo de pesquisa recente, cujos primeiros trabalhos acabam por assumir o papel de conquistar um lugar de respeito dentro de uma determinada comunidade discursiva, que é a comunidade de pesquisadores em Linguística Aplicada.

A seguir, apresentamos um quadro que segue a mesma formatação do QUADRO 5, supracitado, mas dessa vez com trechos extraídos dos resumos e que trazem em si exemplos das materializaçóes textuais que motivaram a identificação das unidades e subunidades retóricas já apresentadas:

\section{QUADRO 6}

Exemplos das materializaçôes textuais que motivaram a identificação das unidades e subunidades retóricas

\section{UR1: Citando conhecimentos prévios / pesquisas que embasam o estudo}

S1: "Uma proposta interacionista sobre aprendizagens de línguas prevê que o aprendiz de uma L2 pode se beneficiar do engajamento em interações com outros falantes, quer nativos ou não nativos, dado o pressuposto de que são reconhecidos, na interação, componentes favoráveis ao avanço desse aprendiz em seu estágio de interlíngua. Neste escopo, a procura, por parte do aprendiz, de garantir a compreensibilidade da sua produção pode conduzir a esforços de negociação de significado, negociação de forma e outros movimentos conversacionais capazes de propiciar condiçōes para que lacunas em seu conhecimento interlinguístico i) emerjam durante a interação; ii) sejam reconhecidas (passem pelo processo da percepção); e iii) sejam revisadas...”. (Apêndice 1, linhas 5-19).

S2: “Os avanços tecnológicos, nos últimos anos, em especial a Internet, no que tange à aprendizagem de línguas estrangeiras, têm perpassado as paredes de sala de aula para trazer para dentro da escola possibilidades variadas de interação entre nativos de diferentes línguas, principalmente devido ao encurtamento de distâncias geográficas, possibilitado pelas ferramentas de comunicação síncrona”. (Apêndice 2, linhas 6-10).

S3: "Como fundamentação teórica, esta pesquisa apresenta estudos sobre: (a) crenças de ensino e aprendizagem e avaliação; (b) avaliação no processo de ensino e aprendizagem; (c) concepções e visões do erro no ensino de línguas; e (d) tecnologia aplicada ao ensino.” (Apêndice 5, linhas 16-19). 
UR2: Apresentando uma espécie de filiação (direta ou indireta) ao projeto Teletandem Brasil: línguas estrangeiras para todos

S1: "O presente estudo se enquadra dentro do projeto pedagógico e tecnológico "Teletandem Brasil: ensino de línguas para todos", o qual objetiva colocar pares de alunos universitários estrangeiros em contato virtual com alunos universitários brasileiros em um ambiente adequado para o ensino de LE." (Apêndice 4, linhas 5-8).

S2: "Esta pesquisa vale-se do contexto de aprendizagem in-tandem tal como é proposto pelo projeto temático (apoiado pela FAPESP) Teletandem Brasil: línguas estrangeiras para todos (TTB) que proporciona situações de comunicação a distância, via ferramentas multimediais de interação pela Internet (por exemplo, o MSN Messenger), em que falantes nativos de línguas diferentes podem ensinar sua língua materna ao outro, em sessōes alternadas de interações." (Apêndice 1, linhas 19-25).

\section{UR3: Apresentando a pesquisa}

S1: "Assim, esta dissertação tem o objetivo de investigar as crenças sobre a avaliação trazidas por uma interagente e uma mediadora ao teletandem, e como essas interagem na construção do processo de ensino e aprendizagem no tandem a distância.” (Apêndice 5, linhas 12-15).

S2: "Neste trabalho de pesquisa no escopo do TTB, lanço mão de um corpus de interaçóes-aula orais gravadas em áudio digital, posteriormente transcrito [...]”. (Apêndice 1, linhas 25-26).

S3: "As asserções que são reveladas por meio da triangulação dos dados gerados nos instrumentos e procedimentos de pesquisa [...]". (Apêndice 6, linhas 20-26).

S4: "Deste modo, este estudo objetivou o desenvolvimento de uma pesquisa qualitativa de cunho etnográfico”. (Apêndice 2, linhas 13-14).

S5: "Os principais resultados apontaram para características interessantes do contexto teletandem no que diz respeito ao tratamento dado à gramática. Observou-se que o foco na forma ocorre com propósitos comunicativos e as sessōes de feedback tem, entre outras funçôes, a de preencher as lacunas do insumo do aprendente. Além disso, notou-se que [...]”. (Apêndice 8, linhas 29-37).

Fonte: Elaboração própria.

De todas as URs destacadas na tabela, apenas a UR3, com suas subunidades, aparece em todos os resumos (UR3: Apresenta a pesquisa; S1: Apresenta os objetivos da pesquisa; e S2: Apresenta os procedimentos de coleta dos dados, tais como observação, gravação, aplicação de questionário, e de sistematização desses dados em corpus de pesquisa - método I; e S3: Apresenta os procedimentos de análise, tais como interpretação, triangulação, inferência, mapeamento - método II; e S4: Apresenta a metodologia que orienta as ações da pesquisa - estudo qualitativo, etnográfico, estudo de caso, paradigma interpretativista etc.; e S5: apresenta os resultados da pesquisa). 
Notamos, por exemplo, que a UR1 (Citando conhecimentos prévios/ pesquisas que embasam o estudo) só aparece nos seis primeiros resumos (que datam de 2008 até 2009) e, de modo semelhante, a UR2 (Apresentando uma espécie de filiação - direta ou indireta - ao projeto TTB) aparece apenas nos sete primeiros resumos de dissertação (que também datam de 2008 até 2009).

Isso fica evidenciado no QUADRO 7, cujo esquema representa a ocorrência de transformaçôes referentes ao apagamento das URs 1 e 2 nas três últimas dissertaçóes publicadas na fase final do projeto TTB. Esse apagamento de URs evoca o conceito de diminuição de esforço retórico (SWALES, 1990, p. 141), que, para Swales, ocorre dentro de uma única materialidade textual, mas que, nesta pesquisa, observamos dentro de um conjunto de publicaçōes de um mesmo gênero textual (resumo de dissertação de mestrado) elaborado por membros de uma mesma comunidade discursiva:

\section{QUADRO 7}

Ilustração da relação entre ordem cronológica das publicaçōes, tempo de pesquisa do projeto TTB e recorrência no uso das unidades retóricas 1 e 2

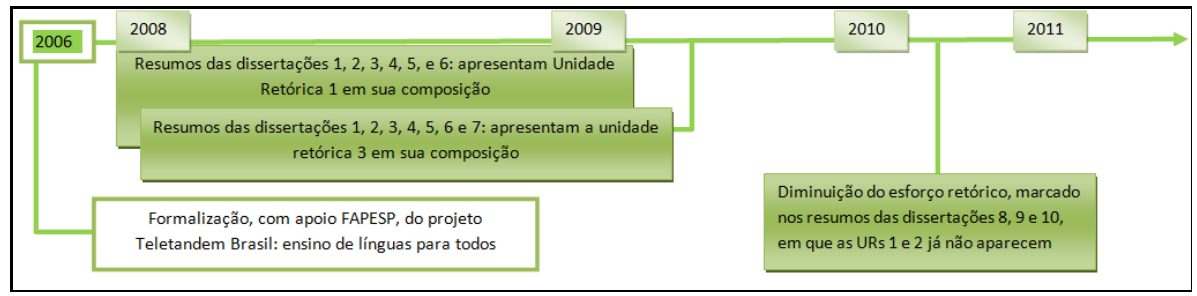

Fonte: Elaboração própria.

Analisando os resumos das dissertaçōes publicadas no escopo do projeto TTB e considerando-os em uma perspectiva temporal linear (do passado para o presente), percebemos que há a diminuição de esforço retórico nesses textos em se justificar os trabalhos de pesquisa, quer seja em face de um campo disciplinar, quer seja em face da filiação a um projeto, em uma tentativa de assegurar a relevância e a validade desses estudos.

Em outras palavras, parece ser amenizada a urgência de se estabelecer a importância da pesquisa em questão aos olhos da comunidade discursiva à qual a dissertação está vinculada, diminui-se "a necessidade de se situar a pesquisa atual em termos de significação, mostrando como esse nicho já estabelecido 
no ecossistema mais amplo será ocupado e defendido" (SWALES, 1990, p. 142, tradução nossa). ${ }^{\text {? }}$

Ainda que tenhamos constatado essa diminuição do esforço retórico, temporalmente marcada pela ausência das URs 1 e 2 nas dissertaçôes 8, 9 e 10, que, não coincidentemente foram as últimas publicadas na fase final projeto TTB, precisamos frisar que essas unidades estão presentes na maioria dos resumos de dissertação que abordamos neste estudo (1, 2, 3, 4, 5, 6). Essa constatação evidencia a complexidade das práticas sociais que engendram e são engendradas pelos gêneros. Bhatia (1997) entende que a dinamicidade, definida como uma tendência à manutenção de sua integridade e, concomitantemente, à busca por renovação, é indício dessa complexidade de que são constituídos os gêneros. (BHATIA, 1997, p. 360).

Pedro Demo (2008) aborda o tema da complexidade enquanto paradigma científico. Isso significa que, para o autor, o conceito de complexidade pode ser utilizado como um horizonte interpretativo de nossas experiências na busca pela construção de nossos conhecimentos. Em outras palavras, a complexidade pode ser entendida como uma perspectiva que transcende os limites disciplinares instituídos em outros paradigmas, capaz de reconhecer o acaso como "fenda na determinação e na predição" (MORIN, 2007, p. 52), como dinâmica de fenômenos que comportariam as seguintes características: a dinamicidade, a não linearidade, a reconstrução, a dialética evolutiva, a irreversibilidade, a intensidade e a ambiguidade/ambivalência.

Ao tratar da dinamicidade, Demo afirma que a complexidade tem em sua identidade a marca do "vir a ser" (DEMO, 2008, p. 13). Segundo o autor, a complexidade configura-se como "campo de forças contrárias", onde a estabilidade é sempre provisória, por isso é dinâmico.

Ora, percebemos que existe um diálogo fundamental entre as reflexões de Bhatia (1997), as reflexões de Demo (2008) e os indícios que destacamos nesta análise ao compararmos os resumos de dissertações de mestrado vinculadas ao projeto TTB, um diálogo que aponta para a complexidade das

\footnotetext{
9 "The need to re-establish in the eyes of the discourse community the significance of the research field itself; the need to situate the actual research in terms of that significance; the need to show how this niche in the wider ecosystem will be occupied and defended. It follows that the amount of rhetorical work needed to create such a space depends on the existing ecological competition, on the size and importance of the niche to be established and on various other factors such as the writer's reputation."
} 
práticas discursivas ligadas a uma comunidade disciplinar como a de pesquisadores em Linguística Aplicada e Estudos Linguísticos.

Ao trabalhar a questão do poder nos gêneros, Bhatia (1997) se propõe a responder como as comunidades disciplinares conseguem manter a integridade do gênero em suas práticas discursivas. Para tecer essa resposta, o autor parte de uma reflexão feita acerca da comunidade acadêmica, através da qual ele ressalta as seguintes características: a intervenção editorial ao recusar ou aceitar determinados artigos acadêmicos; a descrição e citação de pesquisas acadêmicas que precedam a divulgação dos dados de um artigo; o poder de inovação e de incorporação dos gêneros (apontando para uma propensão à fragmentação das convenções de ordem discursiva que exercem o papel mantenedor da integridade do gênero, levando tanto à possibilidade de incorporação e mistura entre gêneros já legitimados, quanto ao surgimento de novos gêneros); as estratégias de manipulação de informações exercidas em comunidades discursivas, restringindo o acesso aos saberes que circulam em dada comunidade apenas aos seus membros; o uso de formas discursivas recorrentes, baseado em representaçôes acerca do que, para os membros de uma determinada comunidade discursiva, serve aos propósitos dessa comunidade. ${ }^{10}$

Essas características ressaltadas por Bhatia (1997) sinalizam tanto certo fechamento que restringe as possibilidades de manifestação textual do gênero acadêmico, quanto uma abertura, marcada pela necessidade de renovação (poder de inovação e de incorporação dos gêneros) que emerge das práticas sociais que subsidiam a existência dos gêneros.

\section{Considerações finais}

A partir da concepção de gênero textual, formulada por Swales (1990; 2004) e Bhatia (1993), constatamos que os resumos de dissertação de mestrado estudados neste artigo trazem em si uma organização retórica que pôde ser classificada em três macrounidades, ou unidades retóricas, sendo elas: UR1: Citando conhecimentos prévios/pesquisas que embasam o estudo; UR2: Apresentando uma espécie de filiação (direta ou indireta) ao projeto TTB; e UR3: Apresentando a pesquisa.

\footnotetext{
${ }^{10} \mathrm{Tal}$ estratégia serviria tanto como forma de reconhecer e legitimar um participante dessa comunidade como um membro - o que, segundo Bhatia, configura-se como solidariedade - quanto serviria para manter os estranhos "a uma distância confortável" (BHATIA, 1997, p. 365).
} 
Com a análise feita neste estudo, identificamos indícios que denotam tanto o poder restritivo ${ }^{11}$ que existe no gênero acadêmico (por meio da identificação das unidades retóricas 1,2 e 3 nas seis primeiras dissertações publicadas pelos pesquisadores vinculados ao projeto TTB) quanto uma espécie de "acomodação" dos pesquisadores nesse nicho (atribuída à ausência das URs 1 e 2 nas três últimas dissertações publicadas por pesquisadores do referido grupo).

Essa "acomodaçâao" se deve ao que chamamos de diminuição do esforço retórico (SWALES, 1990), observada à medida que mais pesquisas vinculadas ao projeto TTB foram sendo divulgadas. Isso nos leva à conclusão de que quanto mais legitimada está a área de pesquisa dentro de uma determinada comunidade discursiva, menor é o esforço retórico despendido pelo pesquisador para que seu trabalho seja reconhecido e validado.

Os resultados deste estudo corroboram a importância de pesquisas que tenham como objetivo refletir sobre as muitas possibilidades de materialização textual do gênero acadêmico, por trazerem contribuiçôes tanto para as comunidades discursivas que sustentam os gêneros acadêmicos, quanto para aqueles pesquisadores que aspiram um lugar dentro desse nicho.

Assim, este estudo possibilita tanto uma metarreflexão dentro das comunidades discursivas, levando a um maior grau de consciência sobre seu próprio fazer científico, quanto possibilita uma troca no fluxo de informaçōes entre as comunidades disciplinares e os futuros pesquisadores. É isso que poderá trazer a emancipação necessária e com a qual Swales, que inspirou tantos trabalhos, inclusive este, sempre se preocupou em promover. ${ }^{12}$

${ }^{11}$ Chamamos de poder restritivo certa estabilidade que pode ser observada nas ações discursivas (MOTTA-ROTH, 2008), e, neste caso, especificamente nas ações da comunidade acadêmica, cujo intuito seria preservar as características dos gêneros que circulam em suas respectivas esferas.

${ }^{12}$ Agradecemos à Dra. Solange Aranha pelas valiosas contribuições e cuidadosa leitura realizada nos manuscritos deste artigo. 


\section{Referências}

ARANHA, S. A argumentação nas introduções de trabalhos científicos da área de Quimica. 1996. 104 f. Dissertação (Mestrado em Linguística Aplicada ao Ensino de Línguas) - Pontifícia Universidade Católica de São Paulo, São Paulo, 1996.

ARANHA, S. Além dos movimentos retóricos: os tipos de verbo como ferramenta de análise. Revista Intercâmbio, São Paulo, v. 14, 2005. Disponível em: <http:/ /revistas.pucsp.br/index.php/intercambio/article/view/3961>. Acesso em: 6 maio 2011.

ASKEHAVE, I. A Functional Interpretation of Company Brochures - From Context to Text. PhD thesis. The Aarhus School of Business, 1998.

ASKEHAVE, I.; SWALES, J. M. Genre Identification and Communicative Purpose: A Problem and a Possible Solution. Applied Linguistics, v. 22, n. 2, p. 195-212, 2001. Disponível em: <http://files.ynada.com/archive/Askehave\% 20 and $\% 20$ Swales $\% 20-\% 20$ Genre\%20 Identification $\% 20$ and $\% 20$ Communicative\%20Purpose.pdf>. Acesso em: 5 maio 2011.

BHATIA, V. K. Analysing Genre: Language Use in Professional Settings. New York: Longman, 1993.

BHATIA, V. K. The Power and Politics of Genre. World Englishes, v. 16, n. 3, p. 359-371, Nov. 1997. Disponível em: <http://www.lingue.uniba.it/dag/pagine/ personale/falco/materiale\%20didattico\%202007-08/Bhatia_power_ politics_genre.pdf $>$. Acesso em: 4 maio 2011.

BEX, T. Variety in Written English. London: Routledge, 1996.

BIASI-RODRIGUES, B. Estratégias de condução de informaçōes em resumos de dissertaçôes. 1998. [?] f. Tese (Doutorado em Linguística) - Centro de Comunicação e Expressão, Universidade Federal de Santa Catarina, Florianópolis, 1998.

BIASI-RODRIGUES, B. O papel do propósito comunicativo na análise de gêneros: diferentes versões. 2007. Disponível em: <http://linguagem.unisul.br/paginas/ ensino/pos/linguagem/cd/Port/28.pdf>. Acesso em: 4 maio 2011.

BIASI-RODRIGUES, B.; ARAÚJO, J. C.; SOUZA, C. S. T. Análise de gêneros na abordagem de Swales: princípios teóricos e metodológicos. In:

(Org.). Gêneros textuais e comunidades discursivas: um diálogo com John Swales. Belo Horizonte: Autêntica, 2009. p. 17-32. (Leitura, Escrita e Oralidade).

BONINI, A. Gênero textual/discursivo: o conceito e o fenômeno. In: CRISTOVÃO, V. L. L.; NASCIMENTO, E. L. (Org.). Gêneros textuais: teoria e prática. Londrina: Moriá, 2004. p. 3-17. 
CARVALHO, F. F. Padrōes de organização textual e lexicogramatical do gênero acadêmico resumo de tese: um estudo de caso. Trabalhos em Linguística Aplicada, Campinas, v. 49, n. 1, p. 115-128, jan.-jun. 2010. Disponível em: <http:// www.scielo.br/pdf/tla/v49n1/09.pdf>. Acesso em: 2 maio 2011.

DEMO, P. Complexidade e aprendizagem: a dinâmica não linear do conhecimento. São Paulo: Atlas, 2008.

HEMAIS, B.; BIASI-RODRIGUES, B. A proposta sócio-retórica de John M. Swales para o estudo de gêneros textuais. In: MEURER, J. L.; BONINI, A.; MOTTA-ROTH, D. (Org.). Gêneros: teorias, métodos, debates. São Paulo: Parábola, 2005. p. 108-129.

MORIN, E. Introdução ao pensamento complexo. Porto Alegre: Sulina, 2007. MOTTA-ROTH, D. Análise crítica de gêneros: contribuições para o ensino e a pesquisa de linguagem. DELTA, São Paulo, v. 24, n. 2, p. 341-383, 2008. Disponível em: <http:/www.scielo.br/pdf/delta/v24n2/v24n2a07.pdf>. Acesso em: 5 maio 2011.

ORLIKOWSKI, W. J.; YATES, J. Genre Repertoire: Examining the Structuring of Communicative Practices in Organizations. Administrative Science Quarterly, v. 39, n. 4, p. 541-574, Dec. 1994. Disponível em: <http://sullivanfiles.net/WID/ assignments/discourse_field/genre_repertoire_orli_yates.pdf>. Acesso em: 5 maio 2011.

SWALES, J. M. Genre Analysis: English in Academic and Research Settings. Cambridge (UK); New York: Cambridge University Press, 1990.

SWALES, J. M. Research Genres: Exploration and Applications. Cambridge (UK); New York: Cambridge University Press, 2004.

TELLES, J. A. Projeto Teletandem Brasil: Línguas Estrangeiras para Todos Ensinando e aprendendo línguas estrangeiras in-tandem via MSN Messenger. 2006. Disponível em: <http://www.teletandembrasil.org/site/docs/TELETANDEM_ BRASIL_completo.pdf>. Acesso em: 7 maio 2011. 